\title{
Article
}

\section{Applying a Communicating Vessels Framework to CSR Value Co-creation: Empirical Evidence from Professional Team Sport Organizations}

Kolyperas, Dimitrios, Anagnostopoulos, Christos, Chadwick, Simon and Sparks, Leigh

Available at http://clok.uclan.ac.uk/15045/

Kolyperas, Dimitrios, Anagnostopoulos, Christos ORCID: 0000-0001-7470-

5191, Chadwick, Simon and Sparks, Leigh (2016) Applying a Communicating Vessels Framework to CSR Value Co-creation: Empirical Evidence from

Professional Team Sport Organizations. Journal of Sport Management, 30 (6). pp. 702-719. ISSN 0888-4773

It is advisable to refer to the publisher's version if you intend to cite from the work. http://dx.doi.org/10.1123/jsm.2016-0032

For more information about UCLan's research in this area go to http://www.uclan.ac.uk/researchgroups/ and search for < name of research Group>.

For information about Research generally at UCLan please go to http://www.uclan.ac.uk/research/

All outputs in CLoK are protected by Intellectual Property Rights law, including Copyright law. Copyright, IPR and Moral Rights for the works on this site are retained by the individual authors and/or other copyright owners. Terms and conditions for use of this material are defined in the policies page. 


\title{
ค)
}

\author{
Applying a Communicating Vessels Framework to CSR Value \\ Co-creation: \\ Empirical Evidence from Professional Team Sport \\ Organizations
}

Kolyperas, D., Anagnostopoulos, C., Chadwick, S., \& Sparks, L.

"As accepted for publication in Journal of Sport
Management, CHuman Kinetics"

doi: 10.1123/jsm.2016-0032 


\begin{abstract}
$^{1}$
Despite the increasing number and significance of charitable foundations in various business sectors, their role in co-creating corporate social responsibility (CSR) value remains unclear. This paper identifies CSR value co-creation in professional team sport organizations (PTSOs) and answers three key research questions: 1) Why have PTSOs developed charitable foundations as their means toward CSR value co-creation? 2) What CSR-related resources do PTSOs and their charitable foundations integrate? and (3) How do they manage, share and transfer such resources in order to co-create CSR value? Drawing theoretical insights from Service Dominant Logic (SDL) and consumer culture theory (CCT) - and using empirical data from 47 semi-structured interviews of UK-based professional football (soccer) clubs this study develops a communicating vessels (CV) framework to illustrate the role of charitable foundations in the CSR value co-creation process. Through four tentative CSR value co-creation levels of relationship (bolt-on, cooperative, controlled, and strategic) the study suggests several internal strategies that can enhance the level of collaboration between founders and foundations. These include information-sharing through CRM systems and social media platforms; staff-sharing or flexible movement across the organizations; quality assurance agreements; flexible team cooperation; partnership protocols with social, media, cultural, and commercial stakeholders; and co-training of personnel.
\end{abstract}

Keywords: CSR value, service dominant logic, consumer culture theory, sport, football, charitable foundations, value co-creation

\footnotetext{
${ }^{1}$ Please direct correspondence to: christos.anagnostopoulos@ himolde.no
} 
Corporate social responsibility (CSR) has increased in practical and academic significance (Breitbarth, Walzel, Anagnostopoulos, \& van Eekeren, 2015; Kudlak \& Low, 2015), subsequently developing diverse practical forms and theoretical avenues (including holistic, social, economic, and industrial), mainly within an overall context of an organization's goal to maximize its long-term positive social impact (McWilliams, Siegel, \& Wright, 2006). While research to understand the value CSR adds to organizations and society as a whole has expanded significantly (e.g., Jamali \& Keshishian, 2009; McWilliams \& Siegel, 2011; Porter \& Kramer, 2011), interest in how charitable foundations help larger organizations in co-creating and managing CSR value has also increased (Minefee, Newman, Isserman, \& Leblebici, 2015). Coca-Cola, Starbucks, BMW, Walmart, Intel, and Nike have all established charitable foundations to achieve strategic CSR value co-creation (Marquardt, 2001). Indeed, drawing on the Fortune 500 companies, Marquis and Lee (2013) revealed that almost 70 percent of the companies in their sample had formed a charitable foundation for their philanthropic activities.

In the context of professional team sport organizations (PTSOs), the practice is not dissimilar (Misener \& Babiak, 2015). Sparvero and Kent (2014) recently reported that 97 of 113 US-based teams have established their own foundation; in England, 89 out of 92 football (soccer) clubs have one (Anagnostopoulos \& Shilbury, 2013), while one in three European football clubs implement their CSR agendas via such nonprofit organizations (Kolyperas \& Sparks, 2011; Walters \& Tacon, 2013). In the UK market, in particular, football clubs are increasingly partnering with local, commercial, and social networks and launching their own independent foundations as the CSR value co-creation mechanism (Anagnostopoulos, Byers, \& Shilbury, 2014; Walters \& Chadwick, 2009). Indeed, football clubs have established charitable foundations (or community trusts), which have organizationally replaced the football-in-the-community (FITC) departmental structure. Brown et al. (2006) noted the shift in institutional forces and the increasing complexity of the industry within which FITC departments operated. The notion of community is becoming more complicated, and charities are organizational formats that are well-positioned in such an evolving environment. Walters (2009) emphasized the organizational value of standardizing CSR foundation models. This would include a greater degree of structural autonomy and responsibility for strategic and financial directions and greater access to public and private funding streams (Walters \& Chadwick, 2009), yet not necessarily diminish the need to balance commercial and social objectives (Anagnostopoulos et al., 2014). 
However, although studies have established charitable foundations as authentic organizations, not simply a façade (Herlin \& Pedersen, 2013; Husted \& Allen, 2007; ReyGarcia, Martin-Cavanna, \& Alvarez-Gonzalez, 2012), researchers have only recently begun to examine the organizational issues involved in replacing in-house social initiatives with foundations, as well as the latter's role in CSR value co-creation (Castro-Martinez \& Jackson, 2015; Misener \& Babiak, 2015; Pedrini \& Minciullo, 2011; Walters \& Panton, 2014). The switch from in-house to independent organizations is not necessarily a straightforward one, as charitable foundations and their founding companies do not automatically share common goals or stakeholder agendas, making for a relationship that is not always conflict-free (Anagnostopoulos \& Shilbury, 2013; Westhues \& Einwiller, 2006). How organizations and their foundations integrate resources in order to capture, co-create, share, transfer, transform (Breitbarth \& Harris, 2008; Husted \& Allen, 2007; Woratschek, Horbel, \& Popp, 2014), or sometimes destroy value (Alessandri et al., 2011; Stieler, Weismann, \& Germelmann, 2014) is a current managerial and research gap.

This study takes up this challenge, and looks into the role of charitable foundations in CSR value co-creation in the sport industry through three research questions: (1) Why have PTSOs developed charitable foundations as their means toward CSR value co-creation? (2) What CSR related-resources do PTSOs and their charitable foundations integrate? and (3) How do these two organizational entities manage, share, and transfer such resources in order to co-create CSR value? Drawing on service dominant logic (SDL) and consumer culture theory (CCT), we develop a communicating vessels (CV) framework to theoretically contribute to the discussion of CSR value co-creation in PTSOs.

The paper is divided into six sections. Following this introduction, section two briefly reviews core literature on CSR, considering the emergence of charitable foundations in sport, and focusing on UK football as a primary context for CSR value co-creation analysis. Section three draws on SDL and CCT insights to theoretically place our discussion on CSR value cocreation into a $\mathrm{CV}$ framework. Section four offers a detailed account of the research design and the method utilized. Drawing on empirical findings, section five answers the three research questions and connects these back to the proposed conceptual framework. The last section discusses managerial and theoretical implications and offers future research avenues. 


\section{Literature Review}

CSR has evolved from a passive ideology, which voluntarily ebbed and flowed on the periphery of organizational activity, into a central approach at the core of corporate strategy (Porter \& Kramer, 2006). The growing organizational importance and role of CSR led to developing charitable foundations as a relevant approach to creating, planning, managing, and distributing CSR value (Herlin \& Pedersen, 2013; Minciullo \& Pedrini, 2015).

A number of internal (organizational) and external (institutional) factors have favored companies' charitable foundations as a divisional way to develop CSR. First, foundations are a formal decentralized means to manage and control CSR, providing a relevant structure and ensuring that philanthropic activities comply with all legal, ethical, and other (normative) guidelines and industry regulations (Cornforth \& Edwards, 1999). Indeed, it is the board of directors that is responsible for the foundation's goals, funding policies, and administration, an organizational structure that constrains individual leaders' influence on corporate philanthropic activities (Marquis \& Lee, 2013). For example, if a PTSO's foundation includes in its "Articles of Agreement" filed with the Charity Commission that the charitable objectives are geared towards young people - five to 25 years of age - then a philanthropic program benefiting elderly pensioners (possibly former professional players who are supported by the parent club) would violate the foundation's objectives, and should not be implemented. Of course, a level of integration with the founding company and other constituencies (such as public, non-governmental, and commercial agents) is guaranteed through the board of trustees. Board members are often current or former CEOs or are drawn from the ranks of other respected individuals (such as lifelong employees, executives, former presidents, or shareholders).

Second, independent foundations offer positive benefits for CSR value co-creation, including enhanced reputation management, brand-building and partnership-generation (Walters \& Chadwick, 2009; Westhues \& Einwiller, 2006). Foundations provide greater access to public, governmental, and commercial funds that were not previously available to the core organization (Herlin \& Pedersen, 2013), and these funds increase the potential capacity for community work (Doherty, Misener, \& Cuskelly, 2014; Misener \& Babiak, 2015). Indeed, as the former commercial director of Charlton Athletic Football Club (currently playing in the third tier of the English football league system) characteristically points out: 
[...] the 'Street Violence Ruins Lives' 2008 CSR campaign resulted in the largest ever sponsorship deal signed by the club including title sponsorship of the foundation $[\ldots]$ raised awareness amongst potential commercial partners $[\ldots]$ unlocked other important sources of funding for sporting organizations and their community operations (Sunderland, 2013, p. 271).

Third, charitable foundations act as sounding boards that attract public goodwill and criticism, and advise the founding organization on CSR-related matters that may arise outside its immediate sphere (Westhues \& Einwiller, 2006). Moreover, foundations often work as "big brothers" and watchdogs, making sure that the founding organizations are proactively planning CSR-related activities with other partners, rather than merely responding reactively to social deficiencies (Hess \& Warren, 2008). For example, Celtic football club's charitable foundation has been quick to partner with the British Red Cross in Glasgow and its Europe Refugee Crisis Appeal in support of refugees and communities across Europe affected by the refugee crisis through a coordinated donation program (www.charity.celticfc.net). This is a testament to how charitable foundations can offer a highly visible way to prioritize CSR initiatives across relevant stakeholders such as media, suppliers, and regulatory agencies, as well as national and international aid charities, in a manner that the parent club would have much more difficulty pursuing (Sunderland, 2013).

However, organizationally restructuring (or outsourcing) CSR activity via charitable foundations has not always been easy or simple to implement (Lindgreen \& Swaen, 2010). Kolyperas, Morrow, and Sparks (2015) mentioned key barriers that PTSO directors in particular face and must overcome when establishing charitable foundations. For instance, the legal status and organizational structure of a foundation can confer potential instability. Although nearly all charitable foundations are tax-exempt, they are peculiarly funded and vulnerable to political change (Bingham \& Walters, 2013). This became evident in the UK, for example, when the 2010 spending review of the coalition government threatened the viability of many charitable organizations highly dependent on public funding (Evans, 2011). Indeed, before the coalition government took office, public funding accounted for approximately 34.5 percent of charities' incomes, with 25 percent of charities receiving some form of government funding (Bingham \& Walters, 2013). Given these organizational and financial characteristics, nonprofit organizations often adopt different ownership structures and require volunteers for operation. Consider, for example, that in the US alone, the broader nonprofit sector that encompasses foundations involves the unpaid labor of 4.7 million full- 
time volunteers - and that, together with the 9.4 million paid employees, people working in the nonprofit sector comprise 11 percent of the American workforce (Bridgeland, McNaught, Reed, \& Dunkelman, 2009).

Furthermore, because foundations are at least partially dependent on their founding PTSO and its network and human resources, they often find it difficult to diversify their agendas and funding portfolios (Bansal, Jiang, \& Jung, 2015; Bingham \& Walters, 2013). Over-reliance on the founding organization creates institutional tensions and constraints. For example, while foundations exist exclusively to pursue projects for the public benefit (Hansmann, 1980), they are often viewed derogatorily as PR vehicles for the founding companies (Toepler, 1996). This dependency leads to excessive closeness that not only jeopardizes foundation independence (turning a "trust" relationship into a "power" relationship), but may also lead some founding companies to exploit their foundations for business means (Westhues \& Einwiller, 2006).

The practical evolution of CSR as a value-based approach in sport has been accompanied by empirical insights on its determinants, pressures, and motives (e.g., Babiak \& Wolfe, 2009; Babiak \& Trendafilova, 2011; Hamil \& Morrow, 2011), and the extent to which PTSOs can obtain any value through their foundations' practices (Extejt, 2004; Inoue, Kent, \& Lee, 2011; Kihl, Babiak, \& Tainsky, 2014). However, still missing from the sport management and marketing literature is an integrative framework - one that would be akin to a more current paradigmatic SDL - for CSR value co-creation. The following section theoretically positions the present study in and around this logic, coupling it with the tenets of CCT (Arnould \& Price, 1993; Arnould \& Thompson, 2005; Price, Arnould, \& Tierney, 1995).

\section{Theoretical Background}

SDL has found theoretical traction - and been able to flourish - in varied sectors of the economy, such as in branding (Merz, He, \& Vargo, 2009; Payne, Storbacka, Frow, \& Knox, 2009), in hospitality (Gareth, Bailey, \& Williams, 2011; Park \& Vargo, 2012), in logistics (Randall, Pohlen, \& Hanna, 2010), in information technology (Yan, Ye, Wuang, \& Hua, 2010), and more recently, in sport (Woratschek et al., 2014; Stieler et al., 2014). However, apart from some notable exceptions from the general management literature (e.g., Sebhatu, 2010), the sport management scholarly community has yet to employ SDL to consider CSR value co-creation, and therefore, the interrelation of the two concepts, as well as the managerial benefits thereof, remain largely unknown. 
According to SDL, value lies in the context and the interactions and mutual exchange processes among multiple service ecosystems of resource-generating actors (for example, the media, star players, the state, fans, sponsors, and commercial/community partners) that simultaneously apply specialized competences (knowledge, skills) and integrate operand (tangible) and operant (intangible) factors in order to co-create value. Such an SDL baseline theoretically aligns with stakeholders' CSR thinking and helps consider more thoroughly CSR value co-creation in the socially constructed and culturally embedded industry of sport along with its interconnected processes, networks, and resources.

PTSOs have dual opportunities for CSR in and through sport (Anagnostopoulos \& Kolyperas, 2015; Breitbarth et al., 2015), either by drawing on their own unique resources to facilitate social image and orient their stakeholder members' experiences (McNamara, Peck, \& Sasson, 2013; Yang \& Sonmez, 2005) or by integrating external resources to serve as vehicles of CSR co-creation for other businesses (Bason \& Anagnostopoulos, 2015; Dowling, Robinson, \& Washington, 2013). Given the unique sociocultural, experiential, symbolic, and ideological characteristics of PTSOs - such as communication power and youth appeal, among others (see Smith \& Westerbeek, 2007), and considering CSR as culture meaning management (Brei \& Böhm, 2011) - consumer culture theory (CCT) has explanatory power to meaningfully define the contextual, idealistic, and symbolic context (and resources) in which CSR value co-creation unfolds (Anagnostopoulos et al., 2014; Castro-Martinez \& Jackson, 2015; Walters \& Chadwick, 2009).

On the one hand, CCT considers the hedonic, aesthetic, and ritualistic dimensions of value co-creation patterns and phenomena (Arnould \& Thompson, 2005; Özsomer \& Altaras, 2008), focusing on the conceptual thematic and brand space, or service-scape, that organizations occupy (Sherry, 1998). On the other hand, PTSOs have historically been used as hubs for political, cultural, business, and humanitarian exchange (Breitbarth \& Harris, 2008) and places where cultural narratives, tales of athletic achievement, and romantic/nostalgic mythologies have been reworked to serve certain social aims and channel fan experiences along certain trajectories (Arnould \& Price, 1993; Joy \& Sherry, 2003). Hence, adding CCT to CSR helps expand the managerial implications of CSR value cocreation from an SDL perspective in sport, and clarifies not only the tangible, but also the intangible, structural, human, contextual, idealistic, and relational resources available to a PTSO's CSR armory such as stadia, museums, players, fans, merchandise, rituals, storytelling, heritage, myths, symbols, identities, and other intellectual properties. 
By fusing SDL with CCT, we introduce a communicating vessels (CV) framework to answer the three research questions and further illustrate the CSR value integration and cocreation process between PTSOs and their charitable foundations. The proposed CV framework bridges CSR value co-creation with SDL and CCT insights and captures three theoretical elements (Figure 1).

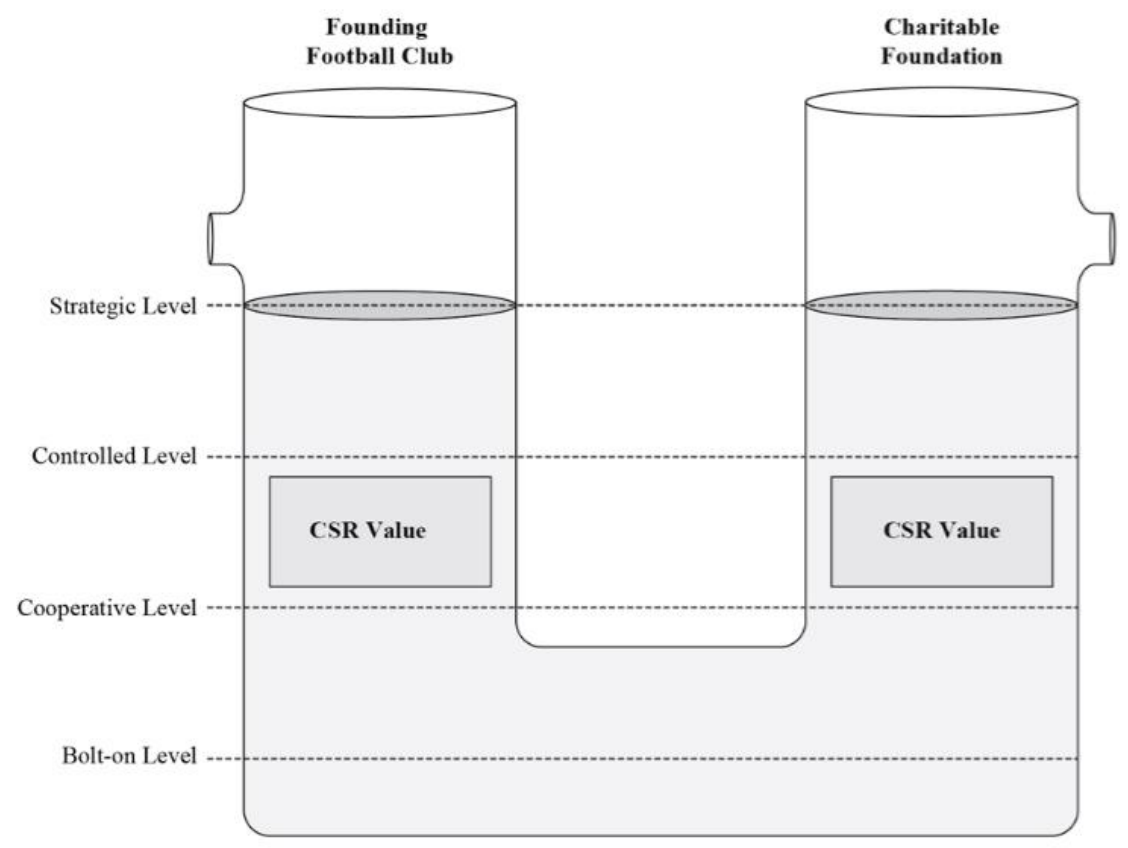

First, the proposed CV framework accommodates a basic level of CSR value cocreation analysis. While it illustrates a degree of association (structural, formal, or informal) between two communicating ecosystems, it highlights the separation between the parent organization and the foundation. Since PTSOs reside in multiple socioeconomic contextspecific spheres, operate across competing institutional logics, and have developed unique idiosyncrasies (Gammelsæter, 2010; Kolyperas \& Sparks; 2011; Kolyperas et al., 2015), the CV framework encompasses CCT and allows for a CSR analysis at an "intra-level" to understand how CSR unfolds across one actor, before focusing on the value it creates for multiple ecosystems.

Second, the proposed CV framework is theoretically in accord with recent revised SDL axioms (Vargo \& Lusch, 2016). Taking into consideration the culturally rich and complex peculiarities of football clubs and the fact that CSR (as a service experience) manifests in dynamic social and cultural service contexts (Akaka, Vargo, \& Schau, 2015), PTSOs and their foundations provide an initial system for exchange of resources uniquely 
perceived by each actor and by the service ecosystem itself (Chandler \& Vargo, 2011). This is in line with what Vargo and Lusch (2015) call "service ecosystems," which capture the interactions, critical energy flow, and mutual service provision between beneficiaries. The present study conceptualizes such flow as an amalgam of CSR-related resources (and CCT elements) ebbing and flowing across two vessels. This conceptualization allows for analysis at a "micro" level as well. It maintains a logic of CSR value transformation - how social problems are being transformed into business opportunities and vice versa - while also highlighting the importance of "value in context" for CSR co-creation (Edvardsson, Tronvoll, \& Gruber, 2011; Vargo, 2009; Vargo et al., 2010).

Third, the proposed CV framework offers an alternative avenue for further conceptualization of CSR value co-creation. The (untapped) CV framework provides room for a more holistic "meso-level" analysis to understand how foundations and their founders attract, integrate, and redistribute resources acquired from actors existing outside their immediate organizational spheres (including sponsors, donors, fans, and the state). This allows for identification of CSR value co-creation levels, and here CCT helps to explain tangible and intangible resource integration. We consider four tentative levels of CSR value co-creation - namely bolt-on, cooperative, controlled, and strategic - although we recognize the fact that the exact shape, impact, and meaning of CSR across football clubs and their charitable arms are highly variable across these four levels, and may also differ in other industrial contexts.

The three theoretical elements of the aforementioned CV framework align with the three questions asked in this study. Focusing on an intra-level of analysis can help us highlight the reasons behind the proliferation of PTSOs' foundations. Moreover, exploring the relationship between founders and foundations from a service-ecosystem point of view fused with CCT elements helps us illustrate the sort of CSR-related value resources the organizations integrate, manage and share, and also how they do it. However, populating the $\mathrm{CV}$ framework with empirical insights serves clarification rather than verification purposes.

\section{Method}

Employing an interpretive approach, we used semi-structured interviews for data collection and analysis. The sample comprises football organizations in the British football industry (England and Scotland). Sixty-six founding football clubs from the top two tiers of 
each country ${ }^{2}$ and their corresponding charitable foundations were contacted by email. Fortyseven interviews were conducted from 2009 to 2012, each lasting an average of 45 minutes. The sample included 26 administrative staff from the charitable foundations ( 21 from England and five from Scotland) and 21 from the founding football clubs (five from England and 16 from Scotland). The majority of the interviews ( $n=43)$ were conducted in face-to-face meetings and took place either in the participants' offices or in rooms within the football stadia booked for this particular purpose. On two occasions, meetings were held in a public space (both in England), while in two cases (both in Scotland), interviews took place over the phone.

Interviewees were key informants for two reasons. First, we recognized that CSR is often a matter of resource availability and other business or individual agendas, so we allowed founding football clubs and foundations to account for their decision-making processes and agendas. Our informants were directors, heads, and senior managers (all called "administrators" here) who are directly responsible for setting strategic goals and overseeing CSR. Second, key personnel from the football clubs offered insights on the role the charitable foundations did or did not have in their overall strategic orientation and day-to-day operational activities. In addition, administrators from the founding football clubs discussed CSR change processes and social drivers behind these changes, along with barriers they faced.

\section{Interview Guide and Procedures}

Drawing on the SDL perspective, we used components of value co-creation in line with the 10 revised fundamental premises of SDL (for more, see Vargo \& Lusch, 2015). Although our research does not sit neatly in the business-nonprofit partnership context - as we see the football club and its foundation more as an inter-organizational collaboration between two service ecosystems - our interviews were additionally guided by Samii et al. (2002) and Kanter (1994), who focused on the key requirements of effective collaborations between businesses and nonprofit organizations. Components such as (operand and operant) resource integration, resource dependency, commitment symmetry, common goal symmetry, intensive communication, alignment of cooperation, learning capability, and converging working cultures (Samii et al., 2002) - as well as individual excellence, importance,

\footnotetext{
${ }^{2}$ Data collection took place before the recent leagues' restructuring in Scottish football, hence the total of 66 football clubs.
} 
interdependence, investment, information, integration, institutionalization, and integrity (Kanter, 1994) - were combined to inform our initial interview guide.

This guide was based on three broad themes relating to the research questions and the theoretical underpinnings of SDL and CCT discussed in our CV framework. The first theme is the CSR's purpose and motivation, as perceived by the organizational actors of both the football club and the charitable foundation. The second theme is the coordination and cocreation mechanics behind the CSR program formulation and implementation including collaborative boundaries and obstacles. The third theme is the perceived pattern of networks and relationships within which CSR is embedded in the organizational ecosystem, including resource allocation, integration, redistribution, and transfer. These themes, and the corresponding questions (see Appendix), were intentionally kept general to allow informants to express their views. All informants were guaranteed anonymity. Transcripts were assigned numbers and letters that correlated to each interview. Interviews with administrators from a football club were labeled $P L-f c l$, while interviews with charitable-foundation administrators were labeled $C F 1$. The number following the letters identifies the specific participant, and only the informant and the authors knew this code.

\section{Data Analysis}

All interview data were recorded and transcribed verbatim, and were analyzed using NVivo 8.0, a qualitative data analysis software program. The analysis followed both inductive and deductive reasoning. Initially, each of the first two authors independently opencoded (Corbin \& Strauss, 2008) the interview material. At this phase, the coding was inductive, with no intention of identifying patterns within the examined data set. Codes were assigned to the data to have a basis upon which axial coding could be applied.

Once broad themes were identified, the software program facilitated the axial coding (Corbin \& Strauss, 2008). In this phase, a more deductive approach was used to quantify, group, and synthesize the data around themes that emerged from phase one and were paired with those identified in the literature (Samii et al., 2002; Kanter, 1994). In total, this second phase of analysis yielded 223 themes (at the axial level). With these themes serving as a codebook, intercode reliability testing using Cohen's kappa was performed resulting in a 0.523 score, which can be interpreted as a moderate level of agreement (Landis \& Koch, 1977). As this was below 0.7, the explanations in the codebook were revised, augmented, and 
fully discussed between both coders to ensure consistency of understanding and interpretation.

Following this process, a second test was performed, and an acceptable intercode reliability score of 0.833 was achieved. The analysis then focused on key elements associated with internal organizational factors and external issues as to why foundations were formed (see RQ1), and subsequently on the resource integration for CSR value co-creation (see RQ2) as well as the transfer and transformation of CSR value resources (see RQ3). This resulted in some "patterns of data" (Patton, 2002, p. 560) that were consistent throughout the data set and across both organizations.

\section{Findings and Discussion}

This section focuses on the three research questions being asked in this study in relation to: (1) the drivers that have led towards the proliferation of foundations; (2) the resources available for CSR value co-creation in the hands of PTSOs and their charitable arms; and (3) the way such resources are transferred and transformed in the pursuit of more sophisticated CSR value co-creation. Using empirical and theoretical insights, our discussion on CSR value co-creation exemplifies the theoretical circumstances involved in the formulation of the proposed CV framework. It is worth noting, however, that for ease of reading - but predominantly as an endeavor to demonstrate the conceptualization process of the $\mathrm{CV}$ framework - the three areas discussed below and the respective themes that "hold them together" are discussed sequentially. However, in practice, these three areas intermingle, and therefore at times the reader may be guided from one area to another between or even within the same subsection.

\section{Reasons behind the Emergence of Charitable Foundations}

Previous literature has credibly argued upon the reasons why PTSOs engage with CSR, highlighting both external and internal forces (e.g., Babiak \& Wolfe, 2013; Babiak \& Trendafilova, 2011; Hamil \& Morrow, 2011; Smith \& Westerbeek, 2007). However, the discussion here "zooms into" those reasons that led specifically to the emergence of the teams' charitable foundations with the view of CSR value co-creation.

For starters, the development of foundations within the UK's football industry was driven by both organizational (internal) and market (external) reasons (Minefee et al., 2015). The findings point out that a football club's power in the community goes beyond organized 
sport and the passion shown by fans (Babiak \& Wolfe, 2009) and employees alike (Anagnostopoulos, Winand, \& Papadimitriou, 2016), the media attention (Smith \& Westerbeek, 2007), and the applicability of the context in itself to provide momentum for a variety of CSR initiatives.

In terms of internal reasons, our informants suggested that the old, in-house structure could not ensure the viable scalability of CSR. As football clubs were increasingly seen as relevant CSR agents, a foundation setup made sure that misalignment of interests between personnel looking after the community side and their counterparts responsible for the business (on-the field) side of operations could be constitutionally overcome. In line with previous empirical studies that reported the dysfunctionality in which organizational actors dealing with these two different agendas find themselves - socially focused and commercially oriented (e.g., Anagnostopoulos et al., 2016; Anagnostopoulos \& Shilbury, 2013; Bingham \& Walters, 2013; Brown et al., 2006) - our empirical findings also point out that the establishment of a charitable foundation offered flexibility in terms of structural independence and autonomous decision-making. As informants from both football clubs and foundations report:

Becoming a company limited by guarantee helped [the community work]... the company itself is a separate legal entity with an autonomous... well, semiautonomous structure due to the board of trustees, in which we (the club) have some seats... it is not the people who own it you see... it is independently run from the people who oversee it. (PL-fc12)

We are fully separated from the club... we have our own responsibilities... they have legal responsibilities to ensure that we meet our charitable purposes which cannot be dictated by the football club. However, there are areas where we can be mutually beneficial to each other and I think both sides now understand that. (CF21)

The emergence of the foundations, therefore, helped eliminate potential conflicts of interest between the two entities and restrict - to various degrees of explicitness - the power of the parent club's personnel to dictate the nature and scope of community-based initiatives. Furthermore, the need to scale up both the quality and the quantity of CSR-based initiatives meant that accessing new resources was imperative. However, funding bodies, such as local authorities, governmental organizations, and third-party agents (including sponsors), were more inclined (at least for legally and constitutional reasons) to link with nonprofit formats than commercialized businesses such as the founding football clubs. 
Before we turned ourselves into a charitable foundation, we were massively dependent on the club's finances and the money coming from the league. As a charity we are still dependent on resources coming in for meeting our statutory objectives, but the pool of people and organizations is larger now; our dependency has been spread out and it's up to us really to cope with challenges relating to capacity, funding, and similar matters. (CF12)

Indeed, our empirical findings align with previous studies on the charitable foundations of PTSOs in the UK and US (see Bingham \& Walters (2013) and Sparvero \& Kent (2014), respectively), which also point out that financial efficiency and overall organizational capacity requires both inward thinking (closer collaboration with the founding sport company) and outward tactics (greater collaboration with the commercial world). The latter is crucial not only because public funds are much more competitive (Walters \& Panton, 2014) and large resource commitments from the parent organization during tough economic times become much harder to obtain (Bansal et al., 2015), but also because firms outside the sport industry demonstrate increased interest in co-creating their CSR agendas through collaboration with nonprofit organizations of this type (Bason \& Anagnostopoulos, 2015; Morrow \& Robinson, 2013). The excerpt below manifests just that:

I think at one time football clubs were very much all about doing nice community programs and generally about delivering after schools, bit of football in school time and holiday camps; that's no longer the case. Football community programs now are seen as capable of working alongside other groups to deliver real and impactful programs. [...] So we now are in the position where we help other organizations deliver their CSR. What happens is they want their staff to be able to do some CSR, well, "What do we go and do? What would be useful?" So they come in and they go in with my coaches and we delivered a reading program in a school together. So in fact what we are doing is we are helping them deliver their CSR and there are a number of organizations who will say, "Look, we can't really deliver, we are not in a place where CSR is easy for us" so they can use us to deliver their CSR, so some of their money will underpin some of our programs. (CF19)

This search for additional resources that would enable a more substantive CSR engagement has therefore led to a greater stakeholder embeddedness, which in turn facilitated a new platform whereby converging and often conflicting political, commercial, and social interests could interact: 
What we do know is that we are now engaging with key stakeholders in the area: senior counselors, local politicians, influential decision-makers; you know, senior business people who have an interest and there is a really positive benefit, not direct but indirect benefit back to the club that we are engaging with these people. That's very positive in that regard and our charity plays a key role towards achieving all of this. (PL-fc22)

Moreover, beyond the abovementioned "internal" reasons, market (external) pressures also explain why the foundation structure has been favored as a relevant setup for CSR value co-creation. More specifically, co-creating CSR through the foundations became a testimony of embodying the culture in which football clubs were initially formed (Hamil \& Morrow, 2011; Walters \& Chadwick, 2009). Organizational actors from both football clubs and foundations acknowledge this, as the following excerpts show:

The heart of the club has been fundamentally grounded in its fans to begin with and its local area and I think really with the previous Chief Executive \{name\}, once we started working on the regeneration of the area with the City Council and the community, it was obvious that that's what we were going to do through the foundation; it's based on values of serving other people and doing the right thing. (PL-FC3)

It is important that the people who are in charge of the brand - and amongst them it is me, of course - understand the brand is there because a lot of people have secured that brand for a long time. So I walk in the footsteps of legends and I am looking after that while I am here; ... if I want to move on and to keep the brand what it is when I leave, but stronger, then I have to secure that. (CF1)

Calls for greater transparency and accountability (Babiak \& Wolfe, 2013; Slack \& Shrives, 2008), as well as pressures provided by the state, other organizations, or the local community contributed towards the proliferation of charitable foundations as a legitimacyseeking mechanisms. Beyond PTSOs' high visibility and often confrontational business practices that have provoked public and media scepticism, our informants highlighted promoting a unique identity, and institutionalizing and externalizing football club values, as well as mimetically synchronizing with other football clubs in the same market. For example, because " [...] funding is generally filtered down by the government whether it comes to interlevel government or whether it goes into our foundations or to a donor who has his/her own foundation" (CF13), the establishment of a nonprofit organization to absorb such funding and 
subsequently respond to local social needs was, perhaps, a straightforward move. Moreover, given that "many large companies are involved with one way or another in CSR, they ultimately ask the question: what programs and how are you doing things in this area?" (CF22), or that "big blue chip companies and corporate foundations...I think in some respects everybody does it this way. So it's something that has to be done because it affects the business, if they are not seen to be doing it" (PL-FC4). Football clubs realize the establishment of foundations was in line with the way other businesses are practicing CSR. On a related note, one participant characteristically stated that "it's starting to drift into football, maybe because there are more business people coming into the game who have come from those organizations that have practiced CSR this way" (CF11), implying that PTSOs established foundations because professionals that are hired to assist in CSR recommend doing it through the foundations route, and not through in-house setups.

\section{Integrating CSR-related Value Resources}

Having offered empirical insights behind the emergence of foundations in the UK's football industry, the study now shifts its attention toward explaining how CSR-related resources are being integrated in and across both organizations through the lenses of SDL and CCT. The former helps consider the role multiple resource-generating actors play in framing CSR in the industry, whereas the latter helps define the symbolic, structural, and other contextual CSR-related resources available to clubs and their foundations.

Our empirical findings show that football clubs are actively involved in a variety of service ecosystems (such as media, retail, and other community networks), yet their individual CSR value co-creation efforts are a function of their embeddedness and adherence to wider CSR policies internationally driven by football's governing bodies and nationally filtered through national business systems (leagues). As a result, football clubs respond to a variety of stakeholder pressures with numerous CSR programs that can be broadly classified into four CSR value co-creation areas - educational programs, sport/health programs, social/cultural inclusion programs, and charity programs. In terms of educational value cocreation, most English football clubs benefit by initiatives taking place in primary and secondary schools designed to encourage pupils to develop lifelong skills, whereas Scottish clubs participate in job fund initiatives, presenting learning/training activities in their venues dedicated to preparing teenagers and adults for employment. 
We have facilities here at the club so the whole program is run here. We have an actual classroom within the stadium; we have two radio training studios the kids use and a TV training studio; there is an actual gymnasium designed only for children and then we have converted a kitchen as well. (CF9)

If you bring the kids down to a football club and you let them look at the stadium and you talk about risk assessments and you talk about match day, non-match day, you take them into the control room, show them how the cameras work; they have seen police on horses and stewards on a match day - they understand. So for us it's very much about what it is as a football club we can do that actually makes some things real for kids. (CF15)

Beyond education-focused initiatives, which are an area that facilitates CSR value exchange between football clubs and various governmental institutions including local councils, universities, the police and other fan, community, and commercial institutions, football clubs sponsor numerous sport/health programs by offering community use of their equipment and resources. Such programs fall under the clubs' immediate expertise because of the health benefits associated with sporting activity (Pringle et al., 2013; Myers et al., 2004). As two administrators from the charitable foundations explain, "we can actually get kids in and teach them how to exercise and how to have fun, we can have more of an effect on it because of our facilities and brand relevance" (CF17) and "boost them in, giving them an experience at this stadium because these will be the future fans." (CF3)

In addition, football clubs intensively address broader social challenges, such as climate change, cultural integration and anti-social behavior; these issues are often accompanied by familiar football-related concerns such as hooliganism, financial problems, racist vilifications, bribery, illegal gambling, or unfair labor practices. In many cases, CSR agendas are tailored towards social issues emerging in communities from which football clubs reside and attract their fans; for example, clubs from London and Manchester address similar local concerns, whereas the "Old Firm Alliance" program initiated by the council of Glasgow against bigotry and sectarianism has brought together the Celtic and Rangers football clubs.

We do become more local in a sense, although our club more often qualifies for international competitions ... so in my experience is very much about - it's not a national brand, we are never going to be a national brand, it's local and I strongly believe that there should be a presence in there at the strategic levels or local 
strategic partnerships where the majority of decision-making is made locally and I think the football club should be at that table. (PL-fc22)

Using their brand reputations and high public profiles, the majority of football clubs were found to be involved in some form of charitable activity as well, often raising funds that are further redistributed to schools, hospitals, other social institutions, or even families in need. Charity trusts linked to a club's core identity, meaning, and heritage are increasing (such as the Celtic Irish Fund for Catholics in diaspora), while more star players and more charitable matches are utilized to raise funds and awareness for worthy causes.

We are currently running a project now called [removed for anonymity purposes], which is using the players as role models to go to community events that we run, to get stories for the press, for radio, television and all those different media outlets. So we use the players to promote what we are doing. (CF4)

I couldn't comprehend how much the [name of FC] branding impacts on what we do, I still am amazed at times. I think it makes you realize quite how much responsibility the players have got. (CF12)

The four areas of CSR value co-creation and the multiple actors identified above indicate CSR maturity (expertise) and sophistication (innovation) in football clubs, and at the same time signify the operand (or tangible - a stadium, a football shirt) and operant (intangible -heritage, image of players, symbolism, identities) resources available in a PTSO's hands.

Your local football club is strong and it probably goes back three, four, five generations, and sometimes we underestimate the privileged position that we have in playing an important role in those people's lives. (PL-fc19)

Our business isn't as big as our brand, our brand is worldwide, the business... we can walk round the corner and walk into 50 businesses on (name of location) Park that are much bigger than ours. Their brand isn't as big as ours, but our brand is huge. (PL-fc1)

Football clubs are socially constructed organizations that reach further in terms of social work due to their image as sport organizations and their integral links to popular culture and CSR activity, attributes that cannot be as easily found in the Starbucks or BMW foundations. Sport organizations have extended legitimacy and a wider CSR footprint that 
allows them to be involved in various collaborative networks without being constantly questioned about their motives. They can activate associational thematic (conceptual and actual) resources (facilities, fans, history, health associations) for their own CSR goals as well as provide other companies with operand and operant resources to achieve their own CSR ends. In doing so, foundations provide relevant structures to plug into existing networks, and unlock, access, and activate contextual resources not previously available (resources that cannot be controlled by one actor) to football clubs.

We use the aura of the football, the aura of our symbols and history, the aura of the stadium, the aura of current and legendary players, and you know, the professional game we use that to engage people - that is our hook to get people involved. So, in that respect that is affected by what's out there, because if we didn't have that, we would just be any other community organization that was trying to do stuff, but we have got that unique selling point that others don't have. (CF10)

I don't think any of our CSR activity could effectively work without partnerships... they bring in all that we just simply wouldn't have... There is no point us just trying to do something on our own because we know we deliver, we deliver the community delivery mechanism and football, but we need to know what people - we need to partner with someone to make sure we are communicating their agenda, that's incredibly important. It would be very, very arrogant for football to say we are just going to run off and do this because we knew best, we don't. We know how to do football, we know how to deliver things in communities, but we are not experts in obesity until we partner with someone, we are not experts in literacy until we partner with someone. (CF2)

CCT has explanatory power with regards to the tangible and intangible CSR-related resources identified above, in that this theory considers the socio-cultural, idealistic, conditional, and symbolic context in which value emerges and CSR unfolds (Özsomer \& Altaras, 2008). In line with CCT, we draw on our empirical findings and identify key structural, human, and relational assets club and foundations hold and, when activated, can help them facilitate CSR initiatives. Such resources are conceptually divided into operand and operant. These resources are illustrated schematically in Table 1 to fit our CV conceptualization. 
Table 1

Operand and operant CSR value resources in professional team sport organizations

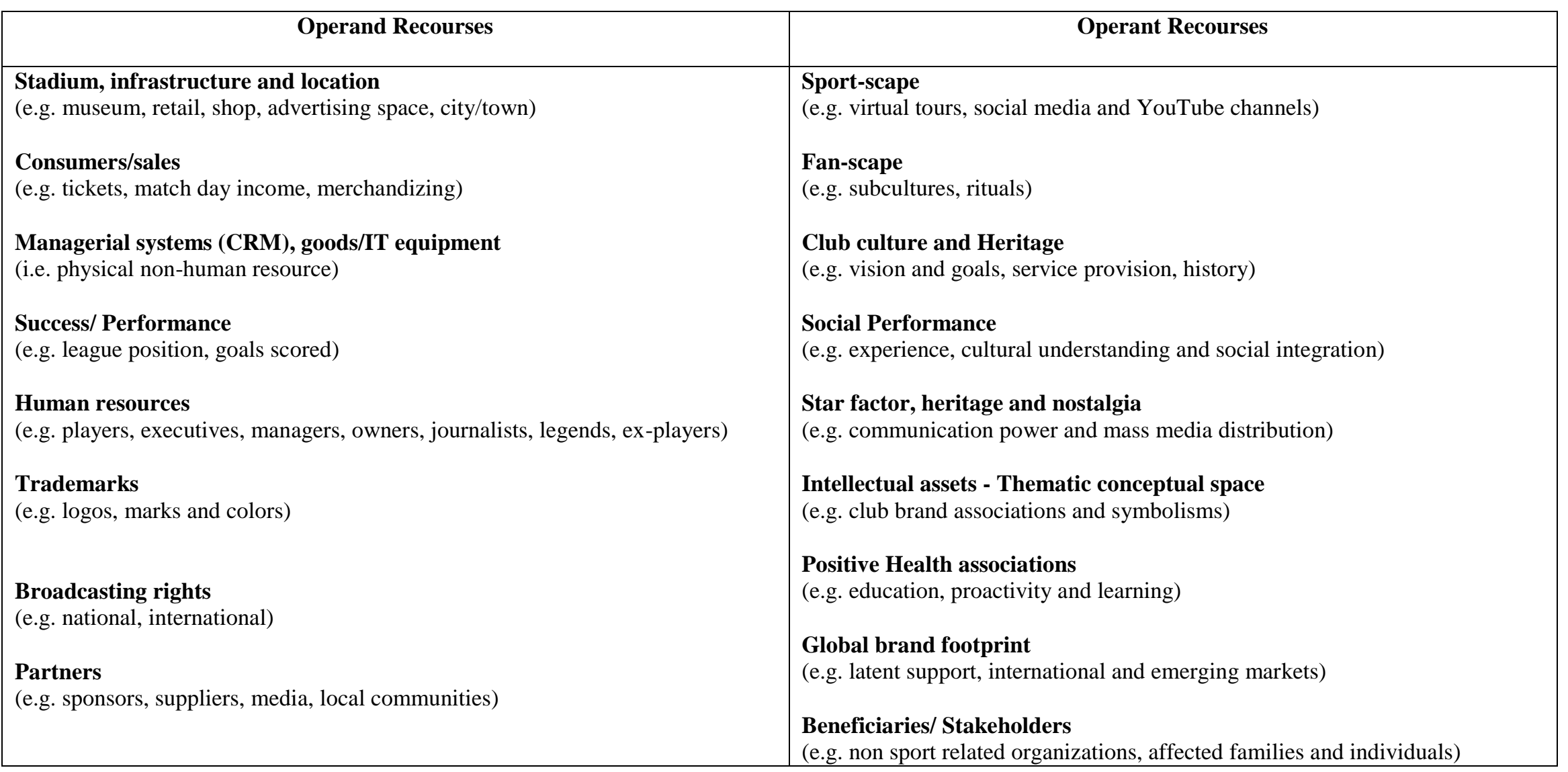




\section{Co-creating, Transferring and Transforming CSR Value Resources}

The third research question, concerning how clubs and foundations manage, share, and transfer resources in order to co-create CSR value, led us to consider closely the relationship between foundations and their respective clubs. There were several instances in which embedded CSR value co-creation was apparent in many different fronts and forms for both the clubs and their foundations. For example, political value creation was evident through lobbying campaigns undertaken with third-party actors and support from the councils; commercial/economic value was developed in the form of attracting sponsorships; and cultural and humanitarian value manifested through authenticity in community initiatives and the latent fan support that followed (Breitbarth \& Harris, 2008). The excerpts below illustrate just two of these fronts:

The foundation is probably our best marketing tool other than a winning football team. So we now embrace them, we support them and they, in turn, go out into the community and spread the name of the club [...] every time we come into contact with a youngster, he or she is potentially a customer; so when I say super marketing tool, that's what I mean. (PL-fc11)

Well, CSR is a value, okay, it doesn't belong to me, I oversee it, promote it, develop it but it's part of everybody's role in the club and that's addressed through information exchange, through training and personal development for every person through very, very high-level promotion of the benefits of our CSR involvement. So hopefully - and we can test it anytime - hopefully right throughout the club everybody is engaged in a day-to-day basis in very, very positive and constructive CSR work. (CF3)

However, both football and foundation administrators highlighted several problematic areas (foundation administrators even more so), including the lack of common CSR definitions, lack of a common strategy and planning, inadequate communication, and lack of information-sharing and staffing:

What I keep telling the football club is that we are not the club's CSR policy, it doesn't really work like that; we can deliver on the club's CSR policy but we are not their CSR policy [...] what I try to say to the club's directors is actually they have a corporate social responsibility, we are already doing this so they should be doing a little bit more. That's where I come from. (CF7) 
We need to get better at branding; we need to get better at work, being clever at what the opportunity we have can do. We have stuff on TV. They don't even mention the foundation. (CF16)

But again, when things are going really well, the communication team is busier, and therefore we have maybe less support. So it's a constant battle to get stories out there, the distinction between us and the club... the most challenging part of my job. (CF12)

For instance, while the CSR goals were explicitly stated and agreed upon, they were more aligned with the foundations' missions and values. For foundations, the CSR objectives and partnerships were established to support their operations and causes, whereas for football clubs, CSR objectives and partnerships were not always linked to the club's strategic goals, often resulting in pressures from the club side as to what sort of initiatives foundations should or could pursue. Such identified power imbalance is in line with previous literature (Toepler, 1996; Westhues \& Einwiller, 2006), and it intensifies in the world of sport, given its loyalty/fandom nature and fan pressures for success on the field. As some administrators from football clubs explicitly state:

Why should we spend money on that and not on a football player? (PL-fc9)

Our driving force is winning football matches, and if social responsibility can be integrated into that, that's fine. (PL-fc2)

We may devalue the brand itself and if you brand yourself to everything, you've always got to understand the value of that badge and you better - I suppose is you better putting your brand to six things that you want to make a real difference and do something really well than to 35 things and then actually your brand gets...and because people come away from it and think - but it that wasn't exactly what - or it wasn't as good as I was expecting... (PL-fc12)

Although revenue generation through CSR practices was a common theme in all cases, it was more obvious within the football clubs. CSR initiatives target consumer markets not previously addressed (such as the elderly, children in need, and women), gain public goodwill and good press, introduce new products and services (such as lotteries, drawings, loyalty programs, and donations) and align with new partners (including commercial sponsors, third-party agents, and local groups). For foundations, revenue generation through 
CSR-related initiatives (mainly fundraising or fees for summer football schools) was not always the prime objective, although their administrators did acknowledge that good CSR means good business. Therefore, achieving a trading surplus (in nonprofit parlance) ensures the foundations' viability.

Our empirical evidence points out different levels of collaboration between foundations and founding football clubs in terms of value co-creation through transferring and transforming CSR-related resources. These levels depend on the degree of CSR-resource integration and/or on the ways the two organizations capture, share, transfer, and transform operand and operant CSR resources to help each other. Drawing on the CV framework, we further develop this logic and propose four CSR value-creation levels, referring to some notable examples in the process.

Bolt-on CSR value co-creation between foundations and football clubs occurs informally for sporadic implementation of joint CSR initiatives with a reactive nature. Such bolt-on initiatives are often done to comply with industrial, cultural, social, and local norms. Christmas charity events are one common type of bolt-on CSR initiative in which foundations and clubs come together. The foundations benefit from access to star players, football legends, historic memorabilia such as cups or shirts, stadium facilities, and museums. Such initiatives are often short-term and reactive, so no metrics are applied.

Cooperative CSR relationships have a short to medium lifecycle. They involve an informal level of information-sharing and some common agendas, whereby social values are somewhat aligned with certain business goals (such as exclusively teaming with a charity that is the sponsor for one season). No metrics are applied, but a considerable recognition of CSR value is apparent in all aspects of the collaboration, including the business side of the founding football clubs.

In controlled CSR relationships, funding is typically medium to long-term across the organizations (such as in the Job Fund case). Self-regulation safeguards and facilitates proactive CSR. Such undertakings are characterized by interagency management teams (between clubs, agents, and the third party), advisory groups, and steering committees, which formalize the goals and metrics of the collaboration by aligning the club's mission with its charitable foundation, as well as its commercial and statutory partners.

A strategic CSR relationship is characterized by intensive interaction levels, CRM information-sharing and targeted communications, alignment/integration of certain processes, and homogenization of organizational culture (such as codes of conduct, dress codes, and 
behavior of staff and fans). Evaluation of business and social objectives is continual, and focuses on continuous improvements and restructuring (such as launching additional new nonprofit trading setups to enable further charitable fundraising and crowd-sourcing).

Successful strategic CSR collaborations between football clubs and charitable foundations are durable and sustainable, often encompassing mechanisms such as quality-assurance agreements, partnership protocols with social, media, cultural, and commercial stakeholders, co-training, resource transferability (for example, the use of star players), and codes of ethics.

\section{Theoretical and Practical Implications}

This section discusses theoretical and practical implications relating to the proposed $\mathrm{CV}$ framework on CSR value co-creation. Drawing on the reasons behind the proliferation of charitable foundations within the PTSOs context, the findings highlight resource availability, structural dependency, brand-building, institutional isomorphism, contextual mimetic practices, and stakeholder embeddedness as being the main factors behind increased CSR practices through these foundations. Along with their foundations, football clubs can draw on a variety of operand and operant resources residing in their contexts and across their interactions with multiple stakeholders. SDL and CCT have helped identify some of the tangible and intangible resources intrinsic in a variety of ecosystems relevant to CSR value co-creation. In addition, the present study considers ways in which CSR value is transferred and transformed between and across football clubs and foundations, and uses a CV framework to illuminate different levels of CSR value co-creation.

The first theoretical contribution of the present study has been to support an emerging stream of conceptual and empirical works calling for the application of more SDL to CSR value co-creation (Woratschek et al., 2014; Vargo \& Lusch, 2016). This paper examined CSR value co-creation between two differing ecosystems and from an inter-organizational perspective, thereby describing a particular institutional context of value co-creation (Bondy et al., 2008; Jackson \& Apostolakou, 2010). Its central thesis is that the emergence of these foundations has been subject to shifting and intensifying stakeholder pressures over time, including institutional and organizational demands. In line with earlier works (Brammer \& Salomon, 2012; Garriga \& Mele, 2004; Verbeke \& Tung, 2013), the takeaway message here is not that more adaptation or higher intensity of CSR practices from foundations will always increase CSR value co-creation. Rather, the study highlights the tradeoffs between operand 
and operant resources that companies and charitable foundations face in their quest for embedded CSR value. The proposed CV framework helps conceptualize these linkages.

Second, examining the practice of CSR through a SDL value co-creation perspective (Vargo \& Lusch, 2015) has led to a closer consideration of the relationship between two particular service ecosystems. The present study draws on CCT to illuminate the resource integration and value transfer across clubs and their foundations, and uses the CV framework to provide understanding on different levels of CSR value co-creation between founding organizations and foundations. The second takeaway message here is that neither organization should necessarily aim for identical or balanced levels of CSR value. That goal might be practically impossible for organizations whose scope of operation, scale, and agendas are different (Anagnostopoulos et al., 2016; Anagnostopoulos \& Shilbury, 2013; Westhues \& Einwiller, 2006). Rather, the authors point out the need for resource integration and transformation (from operand to operant) in the pursuit of more effective CSR value cocreation.

Drawing on the above theoretical implications, companies and their foundations both need to recognize that CSR value co-creation is not a one-dimensional value-based concept; multiple resource-integrating actors interact under the umbrella of CSR in order to co-create value. If other service ecosystems (that is, fans, consumers, media, sponsors, statutory organizations) are able to assess, alter, and reposition the meanings of CSR, often in directions different to what founders and foundations intend, then administrators in both organizational entities should also be prepared to shift operant and operand resources to accommodate such changes.

Our findings have several managerial implications and suggest two different ways (control and transformation) in which PTOs can co-create and utilize CSR value derived within and outside the organizations. Such managerial considerations potentially have a degree of applicability in other service-based industries. However, we do not contend that one strategy that fits all situations exists. Rather, we argue that all companies with foundations should adopt a strategy that combines integration and control as well as respectful observation and constructive transformation when co-creating CSR value.

First, founders and foundations can gain a degree of control by becoming involved in CSR value co-creation activities fostered by other salient stakeholders. This happens, for example, when clubs monitor fan initiatives for CSR issue selection or tap into existing CSR programs of commercial and social partners. Football clubs can opt for passive involvement 
integrating systematic monitoring of several stakeholders' value creation activities and behaviors through social media (and other fora and independent/official websites) in order to observe what key stakeholders relate to and to provide a platform for fan-generated and more targeted CSR marketing. This means that the value of CSR-related initiatives - that is, information and resource flow inside both organizations - is as important as information and assets shared outside and beyond their immediate business sphere.

Second, founders can carefully transform the way they deal with both internal and external stakeholders by utilizing their foundations more in order to develop dialogue. As foundations provide versatile structures and relevant means for channeling financial and intangible resources (brand symbols and core values) in a comprehensive economic environment, they should position themselves on the periphery of organizational activity while maintaining central strategic importance. Especially for those organizations operating in industries that encompass an aspect of fandom, entertainment, and symbolism, foundations are strategically relevant in terms of external partnership attraction. This is because the organizations can manage the extended branding space and thematic world of socially embedded organizations, thereby furthering the inherent and unquestioned applicability of sport contexts for CSR value co-creation.

The abovementioned implies courses of action that do not run counter to the reasons why several stakeholders may choose to autonomously develop CSR (such as fan groups or fan trusts) or engage with the foundation rather than the core organization in the first place. Foundations provide structural autonomy and ease the tension between commercial and community goals. However, such autonomy should be nurtured by top management in order to avoid unwanted compromises and obstacles that may devalue CSR outcomes and restrict collaborations with the outside world. Our findings highlight several internal strategies that can enhance the level of collaboration between founders and foundations. These include information-sharing through CRM systems and social media platforms; staff-sharing or flexible movement across the organizations; formulation of decoupling points (with one administrator responsible for the link between foundation and football club); quality assurance agreements; flexible team cooperation; partnership protocols with social, media, cultural, and commercial stakeholders; and co-training of personnel. 


\section{Conclusions, Limitations and Future Research Directions}

The findings of the present study contribute to our understanding of how CSR value co-creation may occur between PTSOs and their charitable foundations. However, the study is also subject to limitations that we hope other research can take as a starting point for future inquiry. The proposed CV framework with its four layers, supported by some "thick" empirical insights, should be regarded as tentative and in need of substantiation and verification through further research. First, we remain mindful of the influence of context, and have therefore not attempted to offer specific propositions and/or hypotheses that might indicate universality (Ferkins \& Shilbury, 2015). This shortcoming has frequently become an issue for context-specific studies on CSR (Godfrey, Hatch, \& Hansen, 2010), so we encourage researchers to examine whether the proposed CV framework, and its tentative levels of CSR value co-creation, translates to other sporting settings, or to other service ecosystems for that matter. While delving into such studies, a step forward would be to operationalize and test the operand and operant resources that contribute towards CSR value creation, and subsequently develop a typology of best (and less so) practices concerning the relationship between PTSOs and their foundations.

Furthermore, researchers could adopt the proposed CV framework and SDL of CSR value co-creation to contemplate more deeply the interrelationships among different types of actors in CSR value co-creation, across different levels and (sport) service contexts. Such research could pave the way for a better understanding of the intersection points of CSR, SDL, and CCT. In particular, CSR through the lenses of CCT should attract further research attention in culturally rich contexts, such as PTSOs, as well as other entertainment service businesses that encompass various aspects of fandom. Such research could help situate CSR within the conceptual boundaries of SDL and could also provide further insights into the importance of CSR value co-creation through charitable foundations for (sport) business and society as a whole.

Second, the CV framework zooms into a dyad of organizations with a view to highlighting value co-creation at the organizational level of analysis. However, this approach overlooks the fact that a host of diverse interests are pursued by different individuals (managers) in organizations consisting of multiple units (for example, the two vessels proposed here) (Cyert \& March, 1963). As such, although the four tentative levels in the CV framework suggest a degree of managing, sharing, and transferring operand and operant resources towards CSR value co-creation, they offer little at the micro (that is, individual) 
level of analysis. More specifically, if one of the most important determinants of managerial effectiveness is success in influencing subordinates, peers, and superiors (Yukl \& Falbe, 1990), and if, in the absence of formal authority, influence is acquired through principles of reciprocity (Cohen \& Bradford, 1989), examining the type of interpersonal exchanges (or "exchange rates," as per Cohen and Bradford $(1989$, p. 10)) that occur amongst influential organizational actors in both entities (that is, founder and foundation) will help understand what may be needed for greater CSR value co-creation. Thus, instead of a cross-sectional study, a more longitudinal approach could unfold these "microfoundations of CSR" (Aguinis \& Glavas, 2012, p. 956) and uncover further nuances on the relationship between the founder and the foundation.

Third, although empirical insights to the first question touched upon the influence of the institutional environment in which these PTSOs exist and operate, the present study has still adopted an inside-out approach towards the understating of CSR value co-creation. Further research could go beyond the organizational and individual level of analysis and examine CSR value co-creation from a more institutional perspective, thereby adopting an outside-in approach. That is, some of the operand (such as partners) and operant (such as program beneficiaries) CSR value resources discussed herein could offer additional insights into how these external stakeholders perceive CSR value creation by the PTSO's charitable foundations. Therefore, with the CV framework as a basis, one could ask what other elements and factors may weaken or strengthen the collaboration between founders and foundations and how founders and foundations can move from a bolt-on state to higher levels of collaboration with their external environment. Related to the previous point, one could examine the role other external stakeholders play in such processes. For example, there may be room to further conceptualize the $\mathrm{CV}$ framework by adding more vessels (organizations) so that CSR value can flow into and across other service ecosystems.

The aforementioned suggestions for future research are by no means exhaustive. Nevertheless, they should serve as an indicative roadmap towards better understanding of this particular organizational setting through which CSR unfolds, and organizational value is cocreated. It is hoped that the present paper has offered a first step in this direction. 


\section{Acknowledgements}

We are grateful to the Associate Editor Dr Marlene Dixon and the two anonymous reviewers whose supportive and insightful suggestions helped us to improve this work. We also thank participants of the Special Interest Group 'Managing Sport' at the 2014 European Academy of Management (EURAM) conference in Valencia, (Spain), for comments and suggestions made at an earlier draft of this work. Last but not least, we thank all of our interview participants for their time and insights.

\section{References}

Aguinis, H., \& Glavas, A. (2012). What we know and don't know about corporate social responsibility: A review and research agenda. Journal of Management, 38(4), 932-968. doi: $10.1177 / 0149206311436079$

Akaka, M.A., Vargo, S.L, \& Schau, H.J. (2015). The context of experience. Journal of Service Management, 26(2), 206 - 223. doi: http://dx.doi.org/10.1108/JOSM-10-20140270

Alessandri, M.T., Black, S.S., \& Jackson, E.W. (2011). Black economic empowerment transactions in South Africa: Understanding when corporate social responsibility may create or destroy value. Long Range Planning, 44(4), 229-249. doi:10.1016/j.lrp.2011.02.002

Anagnostopoulos, C., Winand, M., \& Papadimitriou, D. (2016) Passion in the workplace: empirical insights from team sport organisations. European Sport Management Quarterly, 16(4), forthcoming. doi: 10.1080/16184742.2016.1178794

Anagnostopoulos, C., \& Kolyperas, D. (2015). Corporate social responsibility. In T. Byers (Ed.) Introduction to Sport Management: A Contemporary Issues Perspective, (pp. 473486). Sage: London.

Anagnostopoulos, C., \& Shilbury, D. (2013). Implementing corporate social responsibility in English football: Towards multi-theoretical integration. Sport, Business, and Management: An International Journal, 3(4), 268-284. doi: http://dx.doi.org/10.1108/SBM-05-2013-0009

Anagnostopoulos, C., Byers, T., \& Shilbury, D. (2014). Corporate social responsibility in team sport organizations: toward a theory of decision-making. European Sport Management Quarterly, 14(3), 259-281. doi:10.1080/16184742.2014.897736 
Arnould, E. J., \& Price, L. L. (1993). River magic: Extraordinary experience and the extended service encounter. Journal of Consumer Research, 20(1), 24-45. doi: http://dx.doi.org/10.1086/209331

Arnould, E. J., \& Thompson, C. J. (2005). Consumer culture theory (CCT): Twenty years of research. Journal of Consumer Research, 31, 868-882. doi: 10.1086/426626

Babiak, K., \& Trendafilova, S. (2011). CSR and environmental responsibility: Motives and pressures to adopt green management practices. Corporate Social Responsibility and Environmental Management, 18(1), 11-24. doi: 10.1002/csr.229

Babiak, K., \& Wolfe, R. (2013). Perspectives on social responsibility in sport. In J. ParamioSalcines, K. Babiak, \& G. Walters (Eds.), Handbook of Sport and Corporate Social Responsibility. (pp. 17-34). London: Routledge Publications.

Bansal, P., Jiang, F.G., \& Jung, C.J. (2015). Managing responsibly in tough economic times: Strategic and tactical CSR during the 2008-2009 global recession. Long Range Planning, 48(2), 69-79. doi:10.1016/j.lrp.2014.07.002

Bason, T., \& Anagnostopoulos, C. (2015). Corporate social responsibility through sport: a longitudinal study of the FTSE100 companies. Sport, Business and Management: An International Journal, 5(3), 218 - 241. doi: org/10.1108/SBM-10-2014-0044

Bingham, T., \& Walters, G. (2013). Financial sustainability within UK charities: Community sport trusts and corporate social responsibility partnerships. VOLUNTAS: International Journal of Voluntary and Nonprofit Organizations, 24(3), 606-629. doi: http://dx.doi.org/10.1007/s11266-012-9275-z

Bondy, K., Matten, D., \& Moon, J. (2008). Multinational corporation codes of conduct: Governance tools for corporate social responsibility?. Corporate Governance: An International Review, 16(4), 294-311. doi: 10.1111/j.1467-8683.2008.00694.x

Brammer, S., \& Salomon, M. (2012). Does it pay to be different? An analysis of the relationship between corporate social and financial performance. Strategic Management Journal, 33(11), 1304-1320. doi: 10.1002/smj.1980

Brei, V., \& Böhm, S. (2011). Corporate social responsibility as cultural meaning management: a critique of the marketing of 'ethical' bottled water. Business Ethics: A European Review, 20(3), 233-252. doi: 10.1111/j.1467-8608.2011.01626.x

Breitbarth, T., \& Harris, P. (2008). The role of corporate social responsibility in the football business: Towards the development of a conceptual model. European Sport Management Quarterly, 8(2), 179-206. doi:10.1080/16184740802024484 
Breitbarth, T., Walzel, S., Anagnostopoulos, C., \& van Eekeren, F. (2015). Corporate social responsibility and governance in sport: 'Oh, the things you can find, if you don't stay behind!'. Corporate Governance: The International Journal of Business in Society, 15(2), 254-273. doi: http://dx.doi.org/10.1108/CG-02-2015-0025

Bridgeland, J.M., McNaught, M., Reed, B., \& Dunkelman, M. (2009). The quiet crisis: The impact of the economic downturn on the nonprofit sector. W.K. Kellog Foundation. Retrieved from www.ndol.org/documents/Quiet_Crisis.pdf.

Brown, A., Crabbe, T., Mellor, G., Blackshaw, T., \& Stone, C. (2006). Football and its communities: Final report. The Football Foundation and Manchester Metropolitan University.

Celtic FC Foundation (2015). Celtic FC Foundation ensure refugees benefit from Jock Stein events. 16 September 2015. Accessed 4 February 2016. http://charity.celticfc.net/

Cohen, A.R., \& Bradford, D.L. (1989). Influence without authority: The use of alliances, reciprocity, and exchange to accomplish work. Organizational Dynamics, 17(3), 5-17.

Corbin, J., \& Strauss, A. (2008). Basics of Qualitative Research. (2nd ed). Thousand Oaks, CA: Sage.

Cornforth, C., \& Edwards, C. (1999). Board roles in the strategic management of non-profit organizations: theory and practice. Corporate Governance: An International Review, 7(4), 346-362. doi: 10.1111/1467-8683.00165

Cyert, R.M., \& March, J.G., (1963). A Behavioural Theory of the Firm. Prentice-Hall, Englewood Cliffs.

Doherty, A., Misener, K., \& Cuskelly, G. (2014). Toward a multidimensional framework of capacity in community sport clubs. Nonprofit and Voluntary Sector Quarterly, 43(2), 124S-142S. doi: 10.1177/0899764013509892

Dowling, M., Robinson, L., \& Washington, M. (2013). Taking advantage of the London 2012 Olympic Games: corporate social responsibility through sport partnerships. European Sport Management Quarterly, 13(3), 269-292. doi:10.1080/16184742.2013.774039

Edvardsson, B., Tronvoll, B., \& Gruber, T. (2011). Expanding understanding of service exchange and value co-creation: A social construction approach. Journal of the Academy of Marketing Science, 39(2), 327-339.

Evans, K. (2011). 'Big society' in the UK: A policy review. Children and Society, 25, 164175. 
Extejt, M. (2004). Philanthropy and professional sport teams. International Journal of Sport Management, 5(3), 215-228.

Ferkins, L., \& Shilbury, D. (2015). Board strategic balance: An emerging sport governance theory. Sport Management Review, 18(4), 489-500. doi:10.1016/j.smr.2014.12.002

Gammelsæter, H. (2010). Institutional pluralism and governance in "commercialized" sport clubs. European Sport Management Quarterly. 10(5), 569-594. doi:10.1080/16184742.2010.524241

Gareth, S., Bailey, A., \& Williams, A. (2011). Aspects of service-dominant logic and its implications for tourism management: Examples from the hotel industry. Tourism Management, 32(2), 207-214

Garriga, E., \& Mellé, D. (2004). Corporate social responsibility theories: Mapping the territory. Journal of Business Ethics, 53(1-2), 51-71. doi:10.1023/B:BUSI.0000039399.90587.34

Godfrey, C., Hatch, W., \& Hansen, M. (2010). Toward a general theory of CSRs: The roles of beneficence, profitability, insurance, and industry heterogeneity. Business \& Society, 49(2), 316-344. doi: 10.1177/0007650308315494

Hansmann, B. (1980). The role of nonprofit enterprise. Yale Law Journal, 89, 835-898.

Herlin, H., \& Pedersen, J. (2013). Corporate foundations: Catalysts of NGO-business partnerships?. Journal of Corporate Citizenship 50 58-90.

Hess, D., \& Warren, D. (2008). The meaning and meaningfulness of corporate social initiatives. Business and Society Review, 113(2), 163-197. doi: 10.1111/j.14678594.2008.00317.x

Husted, W.B., \& Allen, B.D. (2007). Strategic corporate social responsibility and value creation among large firms lessons from the Spanish experience. Long Range Planning, 40, 594-610. doi:10.1016/j.lrp.2007.07.001

Inoue, Y., Kent, A., \& Lee, S. (2011). CSR and the bottom line: analyzing the link between CSR and financial performance for professional teams. Journal of Sport Management, 25(6), 531-549.

Jackson, G., \& Apostolakou, A. (2010). Corporate social responsibility in Western Europe: An institutional mirror or substitute. Journal of Business Ethics, 94(3), 371-394. doi: 10.1007/s10551-009-0269-8 
Jamali, D., \& Keshishian, T. (2009). Uneasy alliances: Lessons learned from partnerships between businesses and NGOs in the context of CSR. Journal of Business Ethics, 84, 277-295. doi: 10.1007/s10551-008-9708-1

Joy, A., \& Sherry, J. F. Jr. (2003). Speaking of art as embodied imagination: A multi-sensory approach to understanding aesthetic experience. Journal of Consumer Research, 30, 25982. doi: $10.1086 / 376802$

Kihl, L., Babiak, K., \& Tainsky, S. (2014). Evaluating the implementation of a professional sport team's corporate community involvement. Journal of Sport Management, 28, 324337. doi: org/10.1123/jsm.2012-0258

Kolyperas, D., \& Sparks, L. (2011). Corporate social responsibility communications in the G25 football clubs. International Journal of Sport Management and Marketing, 10(1/2), 83-103. doi: 10.1504/IJSMM.2011.043612

Kolyperas, D., Morrow, S., \& Sparks, L. (2015). Developing CSR in professional football clubs: drivers and phases. Corporate Governance: The International Journal of Business in Society, 15(2), 177-195. doi: http://dx.doi.org/10.1108/CG-05-2014-0062

Kudlak, R., \& Low K. (2015). Special issues dedicated to CSR and corporate sustainability: A review and commentary. Long Range Planning, 48(3), 215-227. doi:10.1016/j.lrp.2015.03.002

Landis, J.R., \& Koch, G.G. (1977). The measurement of observer agreement for categorical data. Biometrics 33(1), 159-174.

Lindgreen, A., \& Swaen, V. (2010). Corporate social responsibility. International Journal of Management Reviews, 12(1), 1-7. doi: 10.1111/j.1468-2370.2009.00277.x

Marquardt, J. (2001). Corporate Foundation as PR-Instrument. Rahmenbedingungen Erfolgswirkungen, Management, Gabler,Wiesbaden.

Marquis, C. \& Lee, M. (2013). Who is governing whom? Executives, governance, and the structure of generosity in large US firms. Strategic Management Journal, 34(4), 483497. doi: 10.1002/smj.2028

McNamara, P., Peck, S.I., \& Sasson, A. (2013). Competing business models, value creation and appropriation in English football. Long Range Planning, 46, 475-487. doi:10.1016/j.lrp.2011.10.002

McWilliams, A., \& Siegel, S. (2011). Creating and capturing value: Strategic corporate social responsibility, resource-based theory, and sustainable competitive advantage. Journal of Management, 37(5), 1480-1495. doi: 10.1177/0149206310385696 
McWilliams, A., Siegel, S., \& Wright, M. (2006). Corporate social responsibility: Strategic implications. Journal of Management Studies, 43(1), 1-18. doi: 10.1111/j.14676486.2006.00580.x

Merz, M., He, Y., \& Vargo, S.L. (2009). The evolving brand logic: A service-dominant logic perspective. Journal of the Academy of Marketing Science, 37(3), 328-44.

Minciullo, M., \& Pedrini, M. (2015). Knowledge transfer between for-profit corporations and their corporate foundations: Which methods are effective?. Nonprofit Management and Leadership, 25(3), 215-234. doi: 10.1002/nml

Minefee, I., Neuman, E. J., Isserman, N., \& Leblebici, H. (2015). Corporate foundations and their governance: Unexplored territory in the corporate social responsibility agenda. Annals in Social Responsibility, 1(1), 57-75.

Misener, K, \& Babiak, K. (2015). A new 'arena': Social responsibility through nonprofit community sport. Paper presented at the North American Society for Sport Management Conference, June 2-6, Ottawa, Canada.

Morrow, S., \& Robinson, L. (2013). The FTSE-English Olympic Association initiative: A resource dependence perspective. Sport Management Review, 16(4), 413-423. doi:10.1016/j.smr.2013.01.002

Myers, J., Kaykha, A., George, S., Abella, J., Zaheer, N.., Lear, S., Yamazaki, S., \& Froelicher, V. (2004). Fitness versus physical activity patterns in predicting mortality in men. American Journal of Medicine, 117(12), 912-918. doi: http://dx.doi.org/10.1016/j.amjmed.2004.06.047

Özsomer, A., \& Altaras, S. (2008). Global brand purchase likelihood: A critical synthesis and an integrated conceptual framework. Journal of International Marketing, 16(4), 1-28. doi: 10.1509/jimk.16.4.1

Park, S-Y \& Vargo, S.L. (2012). The service-dominant logic approach to tourism marketing strategy. In R.H. Tsiotsou, \& R. Goldsmith Strategic Marketing in Tourism Services, Emerald. (pp. 231-246).

Payne, A., Storbacka, K., Frow, P., \& Knox, S. (2009). Co-creating brands: Diagnosing and designing the relationship experience. Journal of Business Research, 62(3), 379 - 389.

Pedrini, M., \& Minciullo, M. (2011). Italian corporate foundations and the challenge of multiple stakeholder interests. Nonprofit Management and Leadership, 22(2), 173-197. doi: $10.1002 / \mathrm{nml} .20048$ 
Petrovits, M. (2006). Corporate-sponsored foundations and earnings management. Journal of Accounting and Economics, 41(3), 335-362. doi:10.1016/j.jacceco.2005.12.001

Porter, M., \& Kramer, M. (2011). Creating shared value: How to reinvent capitalism-and unleash a wave of innovation and growth. Harvard Business Review, January-February, 2-17.

Price, L. L., Arnould, E., \& Tierney, P. (1995). Going to extremes: Managing service encounters and assessing provider performance. Journal of Marketing, 59(2), 83-97.

Pringle, A., Zwolinsky, S., McKenna, J., Daly-Smith, A., Robertson, S., \& White, A. (2013). Effect of a national programme of men's health delivered in English Premier League football clubs. Public Health, 127(1), 18-26. doi:10.1016/j.puhe.2012.10.012

Randall, W. S., Pohlen, T. L., \& Hanna, J. B. (2010). Evolving a theory of performance based logistics using insights from service dominant logic. Journal of Business Logistics, $31(2), 35-62$.

Rey-Garcia, M., Martin-Cavanna, J., \& Alvarez-Gonzalez (2012). Assessing and advancing foundation transparency: Corporate foundations as a case study. The Foundation Review, 4(3), 77-89. doi: 10.4087/FOUNDATIONREVIEW-D-12-00003.1

Sebhatu, S. P. (2010). Corporate social responsibility for sustainable service dominant logic. International Review on Public and Nonprofit Marketing, 7(2), 195-196.

Sherry, J. (1998). The soul of the company store: Nike Town Chicago and the emplaced brandscape. In J. F. Sherry (Ed.), ServiceScapes: The concept of place in contemporary markets (109-46). Chicago: NTC Business Books.

Slack, R., \& Shrives, P. (2008). Social disclosure and legitimacy in Premier League football clubs: the first ten years. Journal of Applied Accounting, 9(1), 17-28. doi: $10.1108 / 09675420810886105$

Smith, A., \& Westerbeek, H. (2007). Sport as a vehicle for deploying corporate social responsibility. Journal of Corporate Citizenship, 25, 43-54.

Sparvero, E., \& Kent, A. (2014). Sport team nonprofit organizations: Are sport doing well at 'doing good'?. Journal of Applied Sport Management, 6(4), 98-116.

Stieler, M., Weismann, F., \& Germelmann, C.C. (2014) Co-destruction of value by spectators: the case of silent protests. European Sport Management Quarterly, 14(1), 7286. doi:10.1080/16184742.2013.865249 
Sunderland, S. (2013). "Street violence ruins lives": Communicating CSR initiatives. In J. Paramio-Salcines, K. Babiak, \& G. Walters (Eds.), Handbook of Sport and Corporate Social Responsibility. (pp. 263-271). London: Routledge Publications.

Toepler, S. (1996). Das Gemeinn ützige Stiftungswesen in der Modernen Demokratischen Gesellschaft. Ansätze zueiner ökonomischen Betrachtungsweise, Maecenata Verlag, München.

Vargo, S.L., \& Lusch, R.F. (2004). Evolving to a new dominant logic for marketing. Journal of Marketing, 68(1), 1-17. doi: 10.1509/jmkg.68.1.1.24036

Vargo, S.L., \& Lusch, R.F. (2006). Service-dominant logic: what it is, what it is not, what it might be. In R.F. Lusch, \& S.L. Vargo (Eds.), The Service Dominant Logic of Marketing: Dialog, Debate, and Directions (pp. 43-55). Armonk, NY: ME Sharpe.

Vargo, S.L., \& Lusch, R.F. (2016). Institutions and axioms: an extension and update of service-dominant logic. Journal of the Academy of Marketing Science, 44(1), 5-23. doi: $10.1007 / \mathrm{s} 11747-015-0456-3$

Vargo, S.L., \& Lusch, R.F. (2008). Service-dominant logic: continuing the evolution. Journal of the Academy of Marketing Science, 36, 1-10. doi: 10.1007/s11747-007-0069-6

Vargo, S.L., Maglio, P.P., \& Akaka, M.A. (2008). On value and value co-creation: A service systems and service logic perspective. European Management Journal, 26, 145-152. doi:10.1016/j.emj.2008.04.003

Verbeke, A., \& Tung, V. (2013). The future of stakeholder management theory: A temporal perspective. Journal of Business Ethics, 112(3), 529-543. doi: 10.1007/s10551-0121276-8

Walters, G. (2009). Corporate social responsibility through sport: The community sport trust model as a CSR delivery agency. Journal of Corporate Citizenship, 35, 81-94.

Walters, G., \& Tacon, R. (2013). Stakeholder engagement in European football. In J. Paramio-Salcines, K. Babiak, \& G. Walters (Eds.), Handbook of Sport and Corporate Social Responsibility. (pp. 236-248). London: Routledge Publications.

Walters, G., \& Anagnostopoulos, C. (2012). Implementing corporate social responsibility through social partnerships. Business Ethics: A European Review, 21(4), 417-433. doi: 10.1111/j.1467-8608.2012.01660.x

Walters, G., \& Chadwick, S. (2009). Corporate citizenship in football: Delivering strategic benefits through stakeholder engagement. Management Decision, 47(1), 51- 66. doi: http://dx.doi.org/10.1108/00251740910929696 
Walters, G., \& Panton, M. (2014). Corporate social responsibility in professional football. Soccer \& Society, 15(6), 828-846. doi: 10.1080/14660970.2014.920621

Westhues, M., \& Einwiller, S. (2006). Corporate foundations: Their role for corporate social responsibility. Corporate Reputation Review, 9(2), 144-153. doi:10.1057/palgrave.crr.1550019

Woratschek, H., Horbel, C. \& Popp, B. (2014). The sport value framework - a new fundamental logic for analyses in sport management. European Sport Management Quarterly, 14(1), 6-24. doi:10.1080/16184742.2013.865776

Wright, N. D., Claiborne C. B., \& Sirgy, M. J. (1992). The effects of product symbolism on consumer self-concept. In J. F. Jr Sherry, \& B., Sternthal (Eds.), NA - Advances in Consumer Research Vol. 19 (311-318). Provo, UT: Association for Consumer Research.

Yan, J., Ye, K., Wang, H., \& Hua, Z. (2010). Ontology of collaborative manufacturing: Alignment of service oriented framework with service-dominant logic. Expert Systems with Applications, 37(3), 2222-2231.

Yang, D., \& Sonmez, M. (2005). Intangible balls. Business Strategy Review, 16(2), 39-44.

Yukl, G., \& Falbe, C. M. (1990). Influence tactics and objectives in upward, downward, and lateral influence attempts. Journal of Applied Psychology, 75(2), 132-140. 


\section{Appendix}

\section{Interview Guide}

- What sort of operand and operant resources do you integrate to implement CSR?

- What role does the football club play in the charitable foundation (and vice versa)?

- What potential difficulties do you foresee in the relationship between the foundation and its football club?

- Do you see untapped potential in the relationship between the two organizations?

- How do you share value, and how do you define or measure such value?

- Does the founding football club influence the decisions of the foundation's board of trustees?

What are the financial (or other) relationships between the founding football club and the charitable foundation?

- Is there any kind of institutionalized/structured information flow between the charitable foundation and the founding football club?

- Are the founding football club's representatives involved in the charitable foundation's activities in any form? 